\title{
Population Genetics of Fusarium graminearum at the Interface of Wheat and Wild Grass Communities in New York
}

\author{
Michael R. Fulcher, James B. Winans, Menchus Quan, Eniola D. Oladipo, and Gary C. Bergstrom \\ School of Integrative Plant Science, Plant Pathology and Plant-Microbe Biology Section, Cornell University, Ithaca, NY, 14853 \\ Accepted for publication 7 August 2019.
}

\begin{abstract}
Fusarium graminearum is primarily understood as an agricultural pathogen affecting cereal crops, but its host range also includes diverse, noncultivated grasses ubiquitous across agricultural and natural environments. Wild grasses may select for the production of diverse toxin variants (chemotypes) and serve as reservoirs of genetic diversity or sources of disease-inciting inoculum. Populations at the intersection of wheat and wild grass communities were described using 909 isolates collected from wheat spikes, wild grass spikes, and overwintered wild grass stems found at natural and agricultural sites in regions of high and low crop production. Trichothecene (TRI) genotypes correlated to pathogen chemotype were predicted from two loci, and multilocus genotypes (MLGs) were determined using eight microsatellite loci. The genetic diversity of wild grass and wheat-derived populations was comparable, and their differentiation was low. Duplicate MLGs were rare even in samples collected from a single square meter, although they could be found in multiple hosts,
\end{abstract}

ABSTRACT environments, regions, and years. TRI genotype frequencies differed between region and land use. Admixture between TRI genotype-defined populations, which correspond to three previously described sympatric North American populations, was detected and was highest in a region with remote host communities and little agricultural production. Nonagricultural environments may maintain different pathogen TRI genotypes than wheat fields and provide an opportunity for recombination between isolates from different $F$. graminearum populations. A lack of structural barriers suggests that pathogen gene flow is uninhibited between wheat and wild grass communities, and the recovery of putative clones from multiple hosts and environments provides initial evidence that noncultivated grasses are a source of local and regional inoculum.

Keywords: ecology and epidemiology, Fusarium graminearum, grasses, mycology, population biology, wild hosts
Fusarium graminearum Schwabe is best known for causing Fusarium head blight of small grains and Gibberella ear rot of maize but has also been recovered from dozens of noncultivated plants. Able to colonize plants from at least 26 families, $F$. graminearum is most often associated with species in the true grass family, Poaceae (Farr and Rossman 2019). Noncultivated grasses are ubiquitous features of both agricultural and unmanaged landscapes, often found in the margins of crop fields, occupying fallow land, or dominating natural spaces in close proximity to agricultural production (USDA National Agricultural Statistics Service 2019). Despite their widespread distribution and the high frequency of asymptomatic $F$. graminearum colonization reported (Inch and Gilbert 2003; Lofgren et al. 2017; Turkington et al. 2011), the role these hosts play in pathogen evolution and crop disease epidemics is unknown. Understanding pathogen populations at the intersection of crop and noncrop host communities may help determine the importance of these hosts.

$F$. graminearum sensu lato is a globally distributed species complex (O'Donnell et al. 2000, 2004; Starkey et al. 2007; van der Lee et al. 2015) and $F$. graminearum sensu stricto is the dominant species in North America (McMullen et al. 2012; O'Donnell et al. 2004). Three sympatric North American populations exist with overlapping distributions and can be differentiated largely by their

†Corresponding author: G. C. Bergstrom; gcb3@cornell.edu

Funding: National Institute of Food and Agriculture Hatch Project NYC153437 and Agricultural Research Service Agreement Number 59-0206-4-006. The latter is a cooperative project with the U.S. Wheat and Barley Scab Initiative.

*The $\boldsymbol{e}$-Xtra logo stands for "electronic extra" and indicates that two supplementary figures and two supplementary tables are published online.

The author(s) declare no conflict of interest.

(c) 2019 The American Phytopathological Society production of trichothecene toxin variants, which are commonly referred to as chemotypes and correlated with trichothecene (TRI) genotypes (Kelly and Ward 2018). The chemotypes corresponding to North American populations are the 15- and 3-acetylated forms of deoxynivalenol (15ADON and 3ADON, respectively) and the more recently described NX2 (Varga et al. 2015). The NX2 genotype has been found with unusually high frequency in northeastern New York (Lofgren et al. 2018). The distribution of $F$. graminearum TRI genotypes and populations has been the subject of many studies (Astolfi et al. 2012; Guo et al. 2008; Malihipour et al. 2012; Pasquali et al. 2016; Scoz et al. 2009; van der Lee et al. 2015; Wang et al. 2011; Yang et al. 2018; Zhang et al. 2012), though the role of diverse, noncultivated hosts in the maintenance of TRI genotype diversity and structuring of populations has not been investigated.

Pathogen overwintering in crop debris, primarily corn stubble, is implicated as the most significant source of disease-causing inoculum (Leplat et al. 2013). Pathogen survival on infested crop residues results in both local and regional disease pressure (Keller et al. 2014), but the importance of local inoculum production on the tissue of segetal grasses and of regional inoculum resulting from long-term pathogen build-up in unmanaged grasslands where host tissue remains in situ has not been explored. Direct tracking of propagule movement is possible, though challenging (Keller et al. 2011; Prussin et al. 2014); however, drawing inferences about pathogen movement from population genetics is another approach to studying the connection between wild grass debris and disease incidence in crops.

This study was conducted to determine (i) whether wild grasses serve as reservoirs of $F$. graminearum genetic diversity and (ii) how New York populations are structured at the intersection of host communities. If wild grasses were reservoirs of $F$. graminearum diversity, we expected to find higher genotypic or allelic diversity in populations derived from wild grass spikes than from wheat spikes. By extension, we might find higher genetic diversity in 
nonagricultural field sites or in natural environments than in a wheat field or a region containing intensive agricultural production. Although many factors can influence population structure, this study was primarily concerned with the influence of host, physical distance, and predicted membership to previously defined North American populations. Because F. graminearum is capable of kilometer-scale dispersal, it was hypothesized that physical distance would only be associated with differentiation between the most separated isolate sources. This dispersal, coupled with the well-mixed nature of aerial populations (Schmale et al. 2006), led to the expectation that wild grass and crop-derived isolates would show signs of gene flow but that slight population subdivision could occur due to the persistence of local populations surviving between years in accumulated wild grass debris or crop residues. Although sympatric North American populations have been identified, admixture between them has been recorded (Liang et al. 2015; Ward et al. 2008). Because the northern United States and eastern Canada are putative centers of origin for 3ADON- and NX2-producing isolates (Kelly et al. 2015, 2016), we expected admixture between populations would be greater in the northeastern region of New York, where all three populations may have coexisted for a longer period of time.

\section{MATERIALS AND METHODS}

Sampling and Isolates. The isolates used in this study were collected during a 3-year survey of wild grass spikes, naturally senesced and overwintered wild grass stems, and winter wheat spikes (M. R. Fulcher, unpublished data). During the summers of 2015 to 2017, asymptomatic wild grasses (Supplementary Table S1) and symptomatic wheat (unknown winter wheat cultivars) were collected from 23 field sites in two regions of New York that differ in host density (USDA National Agricultural Statistics Service 2019) and $F$. graminearum TRI genotype frequencies (Kuhnem et al. 2015) (Fig. 1). Two land uses, agricultural and nonagricultural (natural), were included in the survey. In all cases, samples were collected from within $1-\mathrm{m}^{2}$ quadrats placed $10 \mathrm{~m}$ apart. At agricultural sites, wheat spikes were collected along transects placed randomly into the field whereas wild grass spikes and stems were collected from field margins. At natural sites, wild grass spikes and stems were collected along transects laid haphazardly in accessible portions of natural preserves. Wild grass stem debris was collected early in the spring to capture only individuals overwintering in place. The collection of spikes from wheat and 12 common wild grass species that have flowering phenology similar to winter wheat was timed to capture the pathogen population after the primary infection cycle occurred but before secondary spike-tospike infection was likely to take place. The isolates chosen for this study $(n=909)$ were morphologically identified as $F$. graminearum sensu lato (Leslie and Summerell 2006) and selected to represent hosts, regions, land uses, and sampling sites as equally as possible (Table 1). Of these isolates, 150 were included specifically because they were collected within single $1-\mathrm{m}^{2}$ quadrats and could be used to observe fine-scale population structure.

Genotyping. Cultures were grown for 2 weeks on potato dextrose agar (PDA) under $12 \mathrm{~h}$ of fluorescent light, mycelium was scraped from the surface of PDA, and samples were frozen at $-20^{\circ} \mathrm{C}$ before tissue disruption. DNA extraction was performed using the QIAGEN DNeasy Plant Mini Kit according to the manufacturer's instructions (Holden, Germany). The TRI genotype of all 909 isolates was determined using two loci. First, a portion of the TRII2 gene was amplified and fragment size was visualized with gel electrophoresis to predict whether isolates would produce nivalenol (NIV), 15ADON, or 3ADON (Starkey et al. 2007). Following this, isolates with a 3ADON genotype were used in a TRII PCRdigestion assay to identify NX2 genotypes (Liang et al. 2014).

A subset of 800 isolates was genotyped at eight previously described microsatellite loci (Supplementary Table S2) (Naef and Défago 2006; Suga et al. 2004; Vogelgsang et al. 2009).
Fluorescently labeled microsatellite primers (Applied Biosystems G5 dye set) were split evenly between two multiplex reactions. The QIAGEN Multiplex PCR Plus Kit was used, and reaction mixtures were $25 \mu \mathrm{l}$ with $0.2 \mu \mathrm{M}$ primer concentrations. The same cycling conditions were used for both reactions: $95^{\circ} \mathrm{C}$ for $5 \mathrm{~min}$; followed by 30 cycles of $95^{\circ} \mathrm{C}$ for $30 \mathrm{~s}, 58^{\circ} \mathrm{C}$ for $1 \mathrm{~min} 30 \mathrm{~s}$, and $72^{\circ} \mathrm{C}$ for $30 \mathrm{~s}$; with a final extension at $72^{\circ} \mathrm{C}$ for $10 \mathrm{~min}$. Amplified products were diluted 1:10 in water, and $1 \mu$ l of diluted product was mixed with $10 \mu \mathrm{l}$ of HiDi Formamide and $0.2 \mu \mathrm{l}$ of GeneScan 500 LIZ size standard (Life Technologies, Woolston, United Kingdom). Fragments were separated on an ABI 3730xl DNA Analyzer at the Cornell Biotechnology Resource Center, and alleles were sized in Geneious Prime (version 2019.0.4; Biomatters, Auckland, New Zealand) using the Microsatellite Analysis plugin, version 1.4.6. A genotype accumulation curve was generated to check the completeness of genotype discovery. Data analyses were performed in RStudio, version 1.1.453 (RStudio Development Team 2016). Microsatellite data were formatted in GenAlex, version 6.503 (Peakall and Smouse 2006, 2012), and individuals with missing allele data were removed prior to analysis in R with the 'poppr', 'adegenet', and 'mmod' packages (Jombart 2008; Kamvar et al. 2014; Winter 2012).

Sources of genetic diversity. Wild grasses were hypothesized to serve as reservoirs of pathogen genetic diversity. In order to test this hypothesis using TRI genotypes and microsatellite multilocus genotypes (MLGs), populations were defined by region, land use, and host source. TRI genotype frequency was analyzed with a multinomial logistic regression implemented in the 'nnet' package (Venables and Ripley 2002) and analysis of variance using TRI genotypes as the response variables and a three-way interaction between region, land use, and host source as the predictor. TRI genotype probabilities were contrasted with 95\% confidence intervals around least-squares means using the 'emmeans' package (Lenth 2019). MLG diversity was measured using rarified MLG counts, Shannon's H (Shannon 1948), Stoddart and Taylor's G (Stoddart and Taylor 1988), Simpson's $\lambda$ (Simpson 1949), and evenness (Pielou 1975). Allele diversity was measured in mean alleles per locus, Simpson's $\lambda$, Nei's gene diversity $H_{\exp }$ (Nei 1978), evenness, and unique alleles.

Sources of genetic structure. Several hypotheses were tested to understand $F$. graminearum genetic structure in New York. First, populations were defined by year, region, land use, and host source. The structure of these populations was evaluated with analysis of molecular variance (AMOVA) using a hierarchical model. A

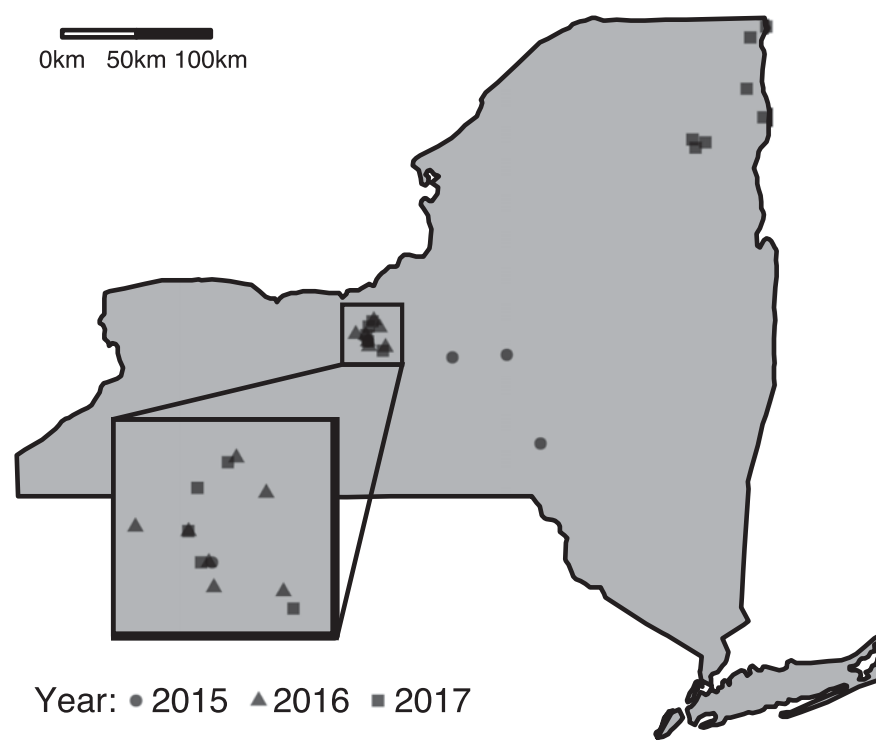

Fig. 1. Fusarium graminearum isolates used in this study were collected over 3 years from 23 field sites situated in two regions of New York. 
random permutation test provided the significance of variance apportioned to each level of the model.

Next, populations were defined solely by host source. Fixation and differentiation indices similar to $\mathrm{F}_{\mathrm{st}}$ (Meirmans and Hedrick 2011), including Hedrick's $\mathrm{G}^{\prime}{ }_{\mathrm{st}}$, Jost's D, and Meirmans $\varphi_{\text {st }}$ (Hedrick 2005; Jost 2008; Meirmans 2006), were calculated to estimate structure between these populations. Bruvo's genetic distance (Bruvo et al. 2004) was also calculated between all pairs of isolates and used to build a minimum spanning network (Prim 1957).

Last, spatial structuring was assessed on two scales. The Bruvo's genetic distance matrix was compared with a physical distance matrix to check for spatial correlation using a Mantel test and a null distribution generated with 10,000 random permutations (Oksanen et al. 2018). In order to measure structure on a fine scale, a subset of the data was used to determine the proportion of duplicate MLGs collected from within $1-\mathrm{m}^{2}$ sampling quadrats. These probabilities were determined based on 11 wild grass debris quadrats from which 5 or 6 isolates were recovered and 12 wild grass spike quadrats from which 5 to 10 isolates were recovered.

Admixture rates. Populations were redefined using TRI genotype, and the hypothesis that admixture between these populations would vary between regions in New York was tested. Five isolates with a NIV genotype were removed from this analysis because of the small sample size. Pairwise differentiation statistics were calculated as described above. A discriminant analysis of principal components (DAPC) was used to visualize the genetic similarity of isolates and to determine the posterior probability of isolate membership to these predefined TRI genotype populations (Jombart et al. 2010). An arbitrary threshold of $80 \%$ posterior probability was used to define isolates showing admixture.

\section{RESULTS}

Sources of genetic diversity. TRI genotype frequencies were contrasted between region, land use, and host source. The production of $15 \mathrm{ADON}$ was predicted for 679 isolates, 3ADON for 201 isolates, NX2 for 24 isolates, and NIV for 5 isolates (Table 1). No variation in TRI genotype frequency was detected between wheat spikes, wild grass spikes, and wild grass debris (Table 2). The probability of a given TRI genotype occurring was significantly affected by both region and land use $(P \leq 0.001)$. The occurrence of 3ADON and NX2 genotypes was greatest in northeastern New York, where agricultural and natural sites contained similar TRI genotype frequencies (Fig. 2). In central New York, the 15ADON genotype was most common but a significant increase in 3ADON genotypes was detected at natural sites compared with agricultural sites (Supplementary Fig. S1).

TABLE 2. Analysis of variance output from a multinomial logistic regression of trichothecene genotype frequencies

\begin{tabular}{lccc}
\hline Predictor & $\chi^{2}$ Statistic & $\begin{array}{c}\text { Degrees of } \\
\text { freedom }\end{array}$ & $P$ value $^{\mathrm{a}}$ \\
\hline Region & 62.345 & 3 & $\mathbf{0 . 0 0 1}$ \\
Land use & 45.416 & 3 & $\mathbf{0 . 0 0 1}$ \\
Host & 7.514 & 6 & 0.276 \\
Region: Land use & 6.987 & 3 & 0.072 \\
Region: Source & 2.490 & 6 & 0.870 \\
Land use: Source & 5.689 & 6 & 0.459 \\
Region: Land use: Source & 4.567 & 6 & 0.600 \\
\hline
\end{tabular}

a Data in bold indicate predictors that explained a significant amount of variation in genotype frequency.

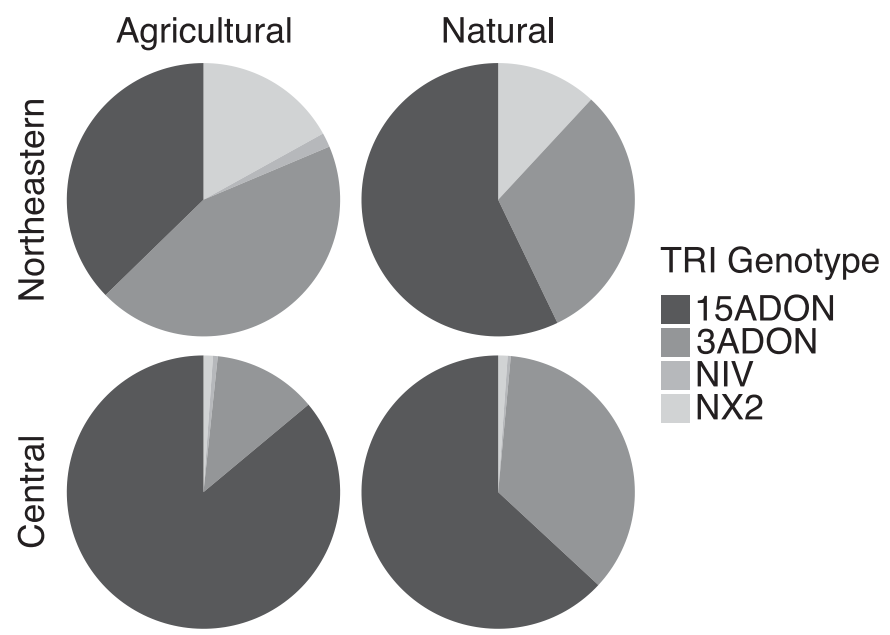

Fig. 2. Trichothecene (TRI) genotype frequencies varied by land use and region. Abbreviations: $15 \mathrm{ADON}$ and $3 \mathrm{ADON}=15$ - and 3 -acetylated forms of deoxynivalenol, respectively, and NIV = nivalenol.

TABLE 1. Population trichothecene (TRI) genotype frequencies and multilocus genotype (MLG) diversity metrics by year, region, land use, and host source ${ }^{\mathrm{a}}$

\begin{tabular}{|c|c|c|c|c|c|c|c|c|c|c|c|}
\hline Year, region & Land use & Host $^{b}$ & $\begin{array}{l}\text { Isolates TRI } \\
\text { genotype }\end{array}$ & $15 \mathrm{ADON}$ & $3 \mathrm{ADON}$ & NIV & NX2 & $\begin{array}{l}\text { Isolate } \\
\text { MLG }\end{array}$ & MLG & Simpson's $\lambda$ & Evenness \\
\hline \multicolumn{12}{|l|}{2015} \\
\hline \multirow[t]{3}{*}{ Central } & \multirow[t]{2}{*}{ Agricultural } & Spikes & 53 & 41 & 10 & 1 & 1 & 52 & 51 & 0.98 & 0.99 \\
\hline & & Wheat & 50 & 36 & 11 & 1 & 2 & 49 & 49 & 0.98 & 1.00 \\
\hline & Natural & Spikes & 12 & 9 & 3 & 0 & 0 & 12 & 11 & 0.90 & 0.96 \\
\hline \multicolumn{12}{|l|}{2016} \\
\hline \multirow[t]{5}{*}{ Central } & \multirow[t]{3}{*}{ Agricultural } & Debris & 236 & 201 & 33 & 0 & 2 & 89 & 88 & 0.99 & 0.99 \\
\hline & & Spikes & 3 & 3 & 0 & 0 & 0 & 2 & 2 & 0.50 & 1.00 \\
\hline & & Wheat & 16 & 12 & 3 & 1 & 0 & 10 & 10 & 0.90 & 1.00 \\
\hline & \multirow[t]{2}{*}{ Natural } & Debris & 103 & 64 & 36 & 1 & 2 & 102 & 95 & 0.99 & 0.96 \\
\hline & & Spikes & 7 & 7 & 0 & 0 & 0 & 7 & 7 & 0.86 & 1.00 \\
\hline \multicolumn{12}{|l|}{2017} \\
\hline \multirow[t]{5}{*}{ Central } & \multirow[t]{3}{*}{ Agricultural } & Debris & 53 & 50 & 2 & 0 & 1 & 51 & 49 & 0.98 & 0.98 \\
\hline & & Spikes & 59 & 54 & 5 & 0 & 0 & 59 & 59 & 0.98 & 1.00 \\
\hline & & Wheat & 68 & 66 & 2 & 0 & 0 & 68 & 67 & 0.98 & 0.99 \\
\hline & \multirow[t]{2}{*}{ Natural } & Debris & 35 & 13 & 21 & 0 & 1 & 35 & 32 & 0.97 & 0.96 \\
\hline & & Spikes & 113 & 77 & 36 & 0 & 0 & 111 & 106 & 0.99 & 0.98 \\
\hline \multirow[t]{6}{*}{ Northeastern } & \multirow[t]{3}{*}{ Agricultural } & Debris & 18 & 6 & 10 & 0 & 2 & 18 & 16 & 0.93 & 0.95 \\
\hline & & Spikes & 12 & 6 & 4 & 0 & 2 & 20 & 20 & 0.95 & 1.00 \\
\hline & & Wheat & 29 & 10 & 12 & 1 & 6 & 23 & 23 & 0.96 & 1.00 \\
\hline & \multirow[t]{3}{*}{ Natural } & Debris & 4 & 3 & 1 & 0 & 0 & 4 & 4 & 0.75 & 1.00 \\
\hline & & Spikes & 38 & 21 & 12 & 0 & 5 & 22 & 22 & 0.95 & 1.00 \\
\hline & & & 909 & 679 & 201 & 5 & 24 & 734 & 680 & 1.00 & 0.96 \\
\hline
\end{tabular}

a Abbreviations: 15ADON and 3ADON $=15$ - and 3-acetylated forms of deoxynivalenol, respectively, and NIV = nivalenol

b Spikes = wild grass spikes and Debris $=$ wild grass debris. 
Microsatellite genotypes were successfully determined for 734 isolates. Samples were removed from the analysis if any microsatellite failed to amplify or if any allele calls were ambiguous. A genotype accumulation curve indicated that almost all genotypes could be detected with seven of the loci chosen (Supplementary Fig. S2). Genotypic diversity was high across all isolate populations, and 680 MLGs were recorded (Tables 1 and 3). Duplicate MLGs were found in isolates collected from different host sources $(n=42$, MLGs $=19)$, land uses $(n=38$, MLGs $=18)$, regions $(n=2, \operatorname{MLG}=1)$, and years $(n=3$, MLG $=1)$. Allele diversity was even across host sources (Table 4).

Sources of genetic structure. According to AMOVA, the majority of genotypic diversity was found within populations (98\%). Year was not a significant source of structure, though region, land use, and host source accounted for slight but significant structure (Table 5). Little genetic differentiation was seen between isolates collected from wild grass spikes, wild grass debris, and wheat spikes $\left(\mathrm{G}^{\prime}{ }_{\mathrm{st}}=0.029, \mathrm{D}=0.017, \varphi_{\mathrm{st}}=0.015\right)$. Plotting the genetic distance between isolates as a minimum spanning network showed no clustering based on host source (Fig. 3). A slight, significant positive correlation was found between genetic and physical distance $(r=0.03, P<0.038)$. The chance of recovering duplicate MLGs from within 1- $\mathrm{m}^{2}$ quadrats ranged from 0 to $10 \%$ for wild grass debris and 0 to $20 \%$ for wild grass spikes, with each averaging $4 \%$.

Admixture rates. Differentiation between TRI genotypedefined populations was greater than for host sources (Table 6), and TRI genotype-defined populations could be separated by a DAPC (Fig. 4). The NX2 population was less differentiated than the $3 \mathrm{ADON}$ and $15 \mathrm{ADON}$ populations. The posterior probability of isolate assignment to TRI genotype populations is displayed in Figure 5. The NX2 genotype was highly admixed and, for all TRI genotypes, admixture was greater in northeastern New York than in central New York (Table 7).

\section{DISCUSSION}

This is the first comprehensive study of the genetic relationship between wild-grass- and wheat-derived $F$. graminearum isolates. The primary goal of this work was to determine whether wild grasses serve as reservoirs of $F$. graminearum diversity. Pathogen genetic diversity was universally high. Most individuals contained a unique MLG, and wheat- and wild-grass-derived populations contained similar levels of allelic diversity at neutral microsatellite loci. However, in central New York, the wild-grass-derived population from nonagricultural sites did contain a different ratio of TRI genotypes than was found in either the wild grasses or wheat at agricultural sites. The wild grasses found in remote, isolated sites in northeastern New York also harbored a different mixture of TRI genotypes, and these isolates showed signs of significant admixture.
This is evidence that wild grasses found in nonagricultural environments may support different pathogen populations than are found at agricultural sites, and that hosts found in remote areas could harbor recombined genotypes and serve as a source of novel genotypic diversity.

The genetic diversity recorded in this study was high and comparable with that found in previous studies focused on cropinfecting $F$. graminearum populations (Liang et al. 2014, 2015; Miedaner et al. 2008) and in one study containing isolates collected from various noncultivated hosts (Sneideris et al. 2018). This high

TABLE 5. Partitioned genotypic variance and significance from hierarchical analysis of molecular variance

\begin{tabular}{lccr}
\hline Source of variance & $\sigma$ & Variance $(\%)$ & $P$ value \\
\hline Between years & -0.05 & -0.86 & 0.849 \\
Between regions & 0.05 & 0.76 & $<0.001$ \\
Between land uses & 0.08 & 1.28 & $<0.001$ \\
Between host sources & 0.04 & 0.64 & 0.013 \\
Within populations & 6.23 & 98.18 & $<0.001$ \\
Total & 6.35 & 100 & $\ldots$ \\
\hline
\end{tabular}

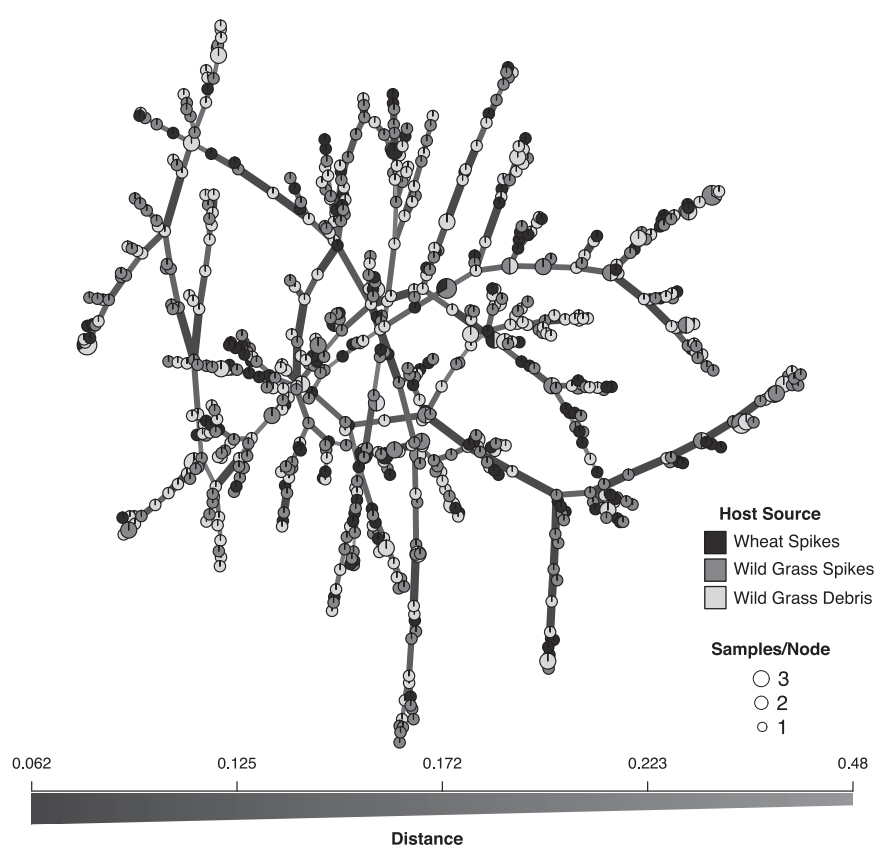

Fig. 3. Minimum spanning tree depicting Bruvo's distance between Fusarium graminearum isolates showed no clustering based on host of origin.

TABLE 3. Genotypic diversity of host defined populations ${ }^{\mathrm{a}}$

\begin{tabular}{lcccccc}
\hline Host & $N$ & MLG & eMLG & Shannon's H & $\begin{array}{c}\text { Stoddart and } \\
\text { Taylor's G }\end{array}$ & Simpson's $\lambda$ \\
\hline Wheat spikes & 150 & 148 & 148 & 4.99 & 146.10 & 0.99 \\
Wild grass spikes & 285 & 274 & 147 & 5.59 & 264.57 & 0.99 \\
Wild grass debris & 299 & 277 & 144 & 5.59 & 259.13 & 0.99 \\
Total & 734 & 680 & 148 & 6.49 & 632.34 & 0.97 \\
\hline
\end{tabular}

${ }^{\mathrm{a}} \mathrm{MLG}=$ multilocus genotype and $\mathrm{eMLG}=$ rarified MLG counts.

TABLE 4. Allelic diversity

\begin{tabular}{|c|c|c|c|c|c|}
\hline Host & $\begin{array}{c}\text { Alleles per } \\
\text { locus }\end{array}$ & $\lambda$ & $\mathrm{H}_{\text {exp }}$ & Evenness & Unique alleles \\
\hline Wheat spikes & 14 & 0.80 & 0.80 & 0.74 & 13 \\
\hline Wild grass spikes & 16 & 0.78 & 0.78 & 0.71 & 13 \\
\hline Wild grass debris & 17 & 0.79 & 0.79 & 0.72 & 20 \\
\hline Total & 16 & 0.78 & 0.78 & 0.72 & $\ldots$ \\
\hline
\end{tabular}


genotypic diversity is a result of outcrossing by $F$. graminearum, and the mutation rate associated with some markers, such as the microsatellites used at present. Duplicate MLGs were rare even within $1-\mathrm{m}^{2}$ patches of wild grass debris and wild grass spikes. On this fine scale, little spatial structure was found and multiple MLGs could be recovered from the spikes or stems of a single host plant. Given this, even small patches of noncultivated grasses may harbor multiple pathogen genotypes or allow unique isolates to recombine.

TABLE 6. Differentiation between populations defined by predicted trichothecene genotypes was measured with Hedrick's $\mathrm{G}_{\text {st }}{ }$ (Jost's D) and Meirmans $\varphi_{\mathrm{st}}{ }^{\mathrm{a}}$

\begin{tabular}{lccc}
\hline Genotypes & 15ADON & 3ADON & NX2 \\
\hline 15ADON & $\ldots$ & $\ldots$ & $\ldots$ \\
3ADON & $0.31(0.26)$ & $\ldots$ & $\ldots$ \\
NX2 & $0.17(0.14)$ & $0.19(0.15)$ & $\ldots$ \\
Universal Meirmans $\varphi_{\text {st }}$ & 0.28 & $\ldots$ & $\ldots$ \\
\hline
\end{tabular}

a Abbreviations: $15 \mathrm{ADON}$ and $3 \mathrm{ADON}=15$ - and 3-acetylated forms of deoxynivalenol, respectively.
The balance of $F$. graminearum TRI genotype frequencies has been the subject of many investigations (Astolfi et al. 2012; Guo et al. 2008; Malihipour et al. 2012; Pasquali et al. 2016; Scoz et al. 2009; van der Lee et al. 2015; Wang et al. 2011; Yang et al. 2018; Zhang et al. 2012). It has been suggested that hosts, environmental factors such as temperature, or the virulence of isolates from different populations are determinants of TRI genotype distribution. In this study, it was clear that pathogen populations collected from winter wheat, wild grass spikes, and wild grass stems occurring in the same field did not differ in TRI genotype composition. This mirrors the results of an earlier study in New York that compared TRI genotype frequencies in isolates collected from wheat, corn, and aerial populations (Kuhnem et al. 2015). As shown in the past, northeastern New York has a uniquely high frequency of the NX2 genotype compared with the other regions where it has been observed (Kelly et al. 2015; Lofgren et al. 2018). The low recovery of NIV genotype isolates is in agreement with previous findings that show a north-south cline and a large population of NIV producers in Louisiana (Gale et al. 2011; Kelly et al. 2015; Schmale et al. 2011). Unlike previous studies that

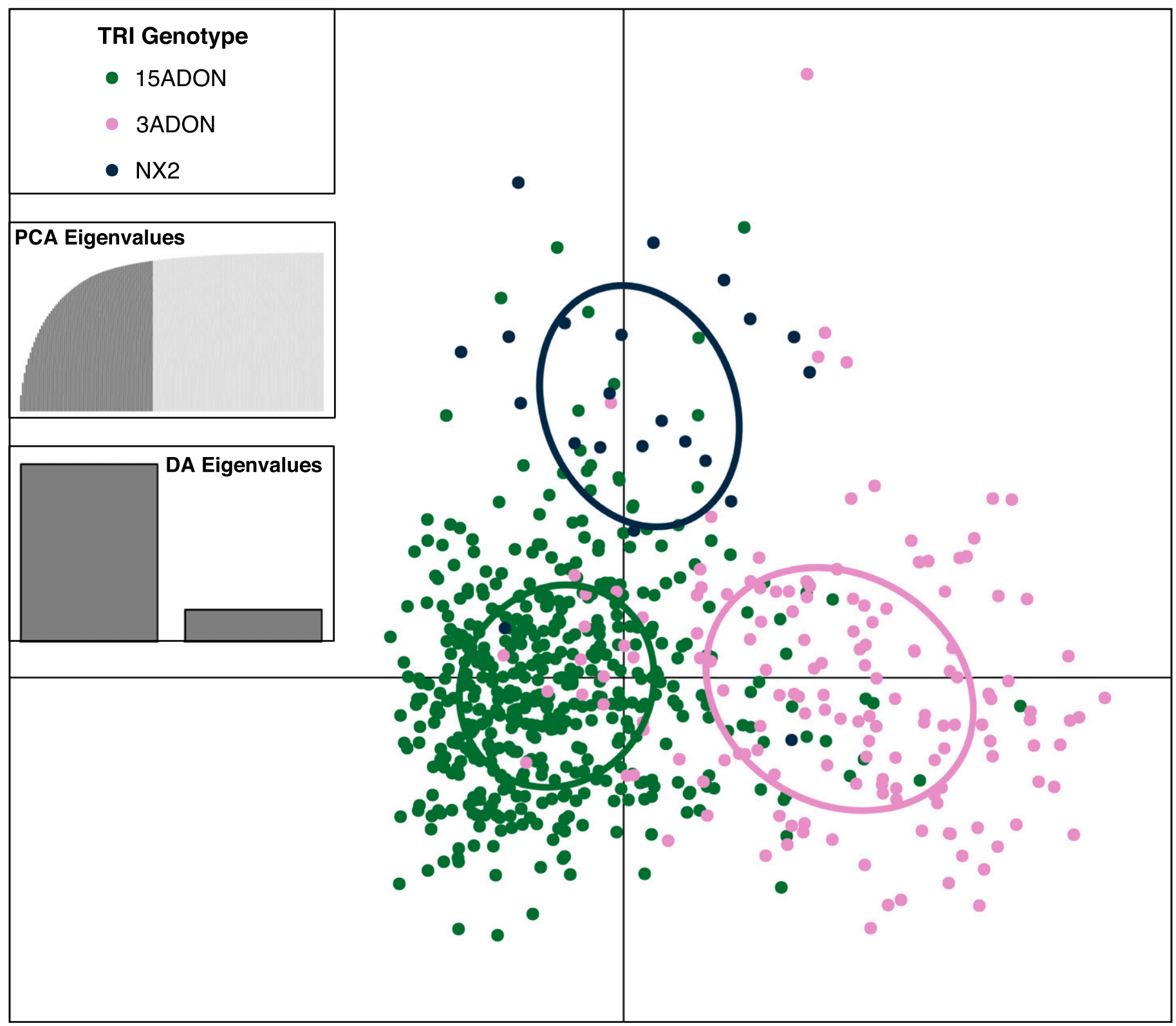

Fig. 4. Scatterplot from a discriminant analysis (DA) of principal components could distinguish three overlapping groups of isolates defined by their trichothecene (TRI) genotype. Abbreviations: PCA = principal component analysis and 15ADON and 3ADON = 15- and 3-acetylated forms of deoxynivalenol, respectively. 
revealed changes in the relative abundance of 15 - and $3 \mathrm{ADON}$ genotypes over time in other parts of North America (Burlakoti et al. 2011; Liang et al. 2014; Ward et al. 2008), the present survey of TRI genotypes from 2015 to 2018 populations presented findings nearly identical to collections made from 2012 to 2013 (Kuhnem et al. 2015) and in 2006 (Schmale et al. 2011). The conditions leading to those well-documented changes in population composition are unlikely to be present in New York.

The reason for the difference in TRI genotype frequency between wild grasses in nonagricultural environments and wild grasses in agricultural fields separated by only 3 to $5 \mathrm{~km}$ is not clear. The increased $3 \mathrm{ADON}$ frequency in these nonagricultural sites in central New York reflects a similar increase in 3ADON frequency in northeastern New York, observed at both agricultural and nonagricultural sites and in all host sources. The similar TRI genotype distributions in these two areas implicates commonalities between their environments such as lower host density or greater host diversity as potentially important factors in shaping TRI genotype distributions. This interpretation is bolstered by previous work associating the relative abundance of different hosts with F. graminearum sensu lato species and TRI genotype distributions (Boutigny et al. 2011; Kuhnem et al. 2016; Sampietro et al. 2011). A shortcoming of this study was an explicit focus on predominantly cool-season wild grasses. Another explanation for differences in TRI genotype frequency in natural spaces could be that warm-season wild grasses flowering later in summer are infected with higher levels of 3ADON-producing isolates and contribute these to local cool-weather wild grasses in subsequent years.

The second goal of this study was to assess pathogen population structure. F. graminearum populations in New York were not strongly structured by host, land use, or year. A weak spatial correlation was found that may relate to the regional difference in TRI genotype distributions. The New York population of $F$. graminearum is strongly structured by TRI genotypes, which correspond to three previously defined North American populations (NA1, NA2, and NA3) (Kelly and Ward 2018). 15ADON (NA1) is predominant in central New York while 3ADON (NA2) and NX2 (NA3) genotypes are found with greater frequency in northeastern New York.

The rates of admixture and differentiation between North American populations of $F$. graminearum has been recorded by several other researchers since Gale et al. (2007) first defined the subdivision of populations associated with 3- and 15ADON TRI genotypes. Although direct comparison is made difficult by variation in the methods and approaches used, prior estimates of admixture and differentiation between these groups are comparable with those reported here. Kelly et al. (2015) described spatial variation in the incidence of recombinant genotypes, and we similarly found elevated signs of admixture in one region of New
York. The increased levels of admixture in northeastern New York could be a result of relatively even TRI genotype frequencies and the prolonged co-occurrence of these populations allowing for more recombination events to occur.

Recent work has identified genomic regions under selection or prone to recombination events (Kelly and Ward 2018, Talas and McDonald 2015). Isolates from noncrop hosts may be of particular interest in future genome analysis projects attempting to identify genes with adaptive function. $F$. graminearum-infected wild grasses are typically asymptomatic under natural conditions and do not accumulate mycotoxins to the extent observed in crop infection (Lofgren et al. 2017), indicating that successful colonization is facilitated by yet-to-be-discovered traits. For this reason, the host-fungus relationship between $F$. graminearum and wild grasses should be further characterized, particularly with respect to the selective pressures that exist in nonagricultural environments and how they contribute to the maintenance of agriculturally relevant pathogen phenotypes (for instance, fungicide resistance or toxin production).

Wild grasses may be important for their contribution of inoculum to crop disease epidemics. The movement of pathogen propagules between hosts and land uses does not appear inhibited by population structure, and several putative clones were found across multiple hosts and land uses. Because the number of putative clones identified based on isolates containing identical MLGs can be inflated due to size homoplasy of microsatellite alleles, this finding should be considered with caution (Estoup et al. 2002). Despite this, the combination of direct and indirect evidence suggests that noncultivated grass hosts are a substrate for the production of both local and regional inoculum. The relative importance of this compared with inoculum arising from agricultural crop residues such as corn stubble remains to be determined.

TABLE 7. Admixture rates of trichothecene (TRI) genotype-defined populations

\begin{tabular}{llc}
\hline TRI genotype & \multicolumn{1}{c}{ Region } & $\begin{array}{c}\text { Admixed } \\
\text { proportion }^{\mathrm{b}}\end{array}$ \\
\hline 3ADON & Central & 0.35 \\
& Northeastern & 0.53 \\
15ADON & Central & 0.12 \\
NX2 & Northeastern & 0.19 \\
& Central & 0.67 \\
& Northeastern & 0.72
\end{tabular}

a Abbreviations: $15 \mathrm{ADON}$ and $3 \mathrm{ADON}=15$ - and 3-acetylated forms of deoxynivalenol, respectively.

${ }^{\mathrm{b}}$ Having $\leq 80 \%$ assignment probability to the TRI genotype-defined population.

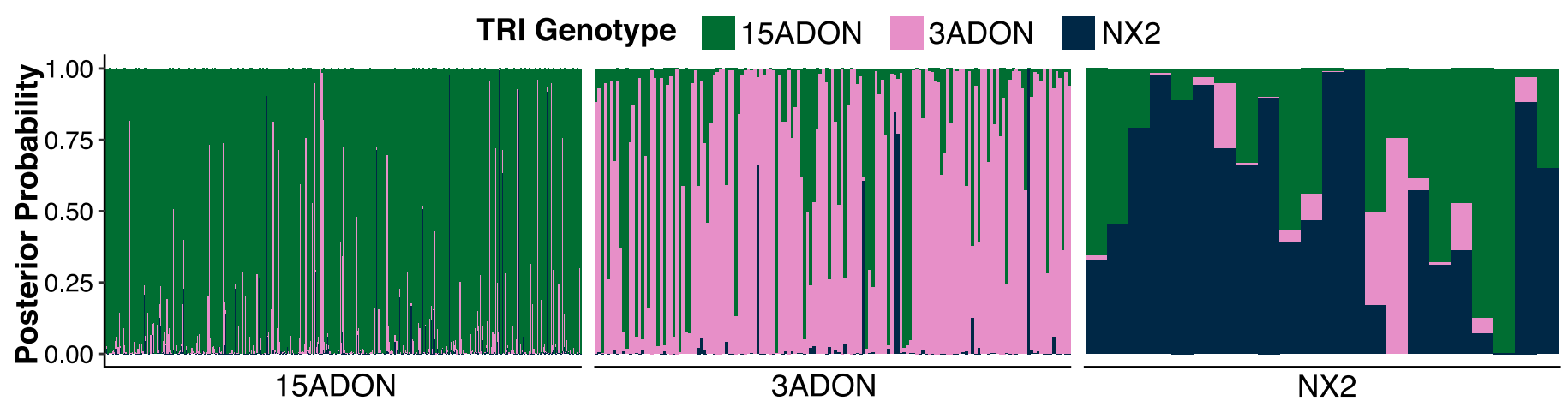

Fig. 5. Posterior probabilities of isolate assignment to trichothecene (TRI) genotype defined populations after a discriminant analysis of principal components indicated significant admixture. Abbreviations: $15 \mathrm{ADON}$ and $3 \mathrm{ADON}=15$ - and 3-acetylated forms of deoxynivalenol, respectively. 


\section{ACKNOWLEDGMENTS}

We thank Extension Specialists K. Severson, M. Stanyard, and K. O'Neil; C. Nobles and the Uihlein Seed Potato Farm; M. Davis and Willsboro Research Farm; L. Ziemba and the Montezuma National Wildlife Refuge; and the small grains producers who assisted with sampling.

\section{LITERATURE CITED}

Astolfi, P., Reynoso, M. M., Ramirez, M. L., Chulze, S. N., Alves, T. C., Tessmann, D. J., and Del Ponte, E. M. 2012. Genetic population structure and trichothecene genotypes of Fusarium graminearum isolated from wheat in southern Brazil. Plant Pathol. 61:289-295.

Boutigny, A. L., Ward, T. J., Van Coller, G. J., Flett, B., Lamprecht, S. C., O'Donnell, K., and Viljoen, A. 2011. Analysis of the Fusarium graminearum species complex from wheat, barley and maize in South Africa provides evidence of species-specific differences in host preference. Fungal Genet. Biol. 48:914-920.

Bruvo, R., Michiels, N. K., D’Souza, T. G., and Schulenburg, H. 2004. A simple method for the calculation of microsatellite genotype distances irrespective of ploidy level. Mol. Ecol. 13:2101-2106.

Burlakoti, R. R., Neate, S. M., Adhikari, T. B., Gyawali, S., Salas, B., Steffenson, B. J., and Schwarz, P. B. 2011. Trichothecene profiling and population genetic analysis of Gibberella zeae from barley in North Dakota and Minnesota. Phytopathology 101:687-695.

Estoup, A., Jarne, P., and Cornuet, J. M. 2002. Homoplasy and mutation model at microsatellite loci and their consequences for population genetics analysis. Mol. Ecol. 11:1591-1604.

Farr, D. F., and Rossman, A. Y. 2019. Fungal Databases, U.S. National Fungus Collections. United States Department of Agriculture-Agricultural Research Service. https://nt.ars-grin.gov/fungaldatabases/

Gale, L. R., Harrison, S. A., Ward, T. J., O’Donnell, K., Milus, E. A., Gale, S. W., and Kistler, H. C. 2011. Nivalenol-type populations of Fusarium graminearum and $F$. asiaticum are prevalent on wheat in southern Louisiana. Phytopathology 101:124-134.

Gale, L. R., Ward, T. J., Balmas, V., and Kistler, H. C. 2007. Population subdivision of Fusarium graminearum sensu stricto in the Upper Midwestern United States. Phytopathology 97:1434-1439.

Guo, X. W., Fernando, W. G. D., and Seow-Brock, H. Y. 2008. Population structure, chemotype diversity, and potential chemotype shifting of Fusarium graminearum in wheat fields of Manitoba. Plant Dis. 92:756-762.

Hedrick, P. W. 2005. A standardized genetic differentiation measure. Evolution 59:1633-1638.

Inch, S., and Gilbert, J. 2003. The incidence of Fusarium species recovered from inflorescences of wild grasses in southern Manitoba. Can. J. Plant Pathol. 25:379-383.

Jombart, T. 2008. Adegenet: A R package for the multivariate analysis of genetic markers. Bioinformatics 24:1403-1405.

Jombart, T., Devillard, S., and Balloux, F. 2010. Discriminant analysis of principal components: A new method for the analysis of genetically structured populations. BMC Genet. 11: Article 94.

Jost, L. 2008. $\mathrm{G}_{\mathrm{ST}}$ and its relatives do not measure differentiation. Mol. Ecol. 17:4015-4026.

Kamvar, Z. N., Tabima, J. F., and Grünwald, N. J. 2014. Poppr: An R package for genetic analysis of populations with clonal, partially clonal, and/or sexual reproduction. PeerJ 2:e281.

Keller, M. D., Bergstrom, G. C., and Shields, E. J. 2014. The aerobiology of Fusarium graminearum. Aerobiologia 30:123-136.

Keller, M. D., Thomason, W. E., and Schmale, D. G. 2011. The spread of a released clone of Gibberella zeae from different amounts of infested corn residue. Plant Dis. 95:1458-1464

Kelly, A. C., Clear, R. M., O’Donnell, K., McCormick, S., Turkington, T. K., Tekauz, A., Gilbert, J., Kistler, H. C., Busman, M., and Ward, T. J. 2015. Diversity of Fusarium head blight populations and trichothecene toxin types reveals regional differences in pathogen composition and temporal dynamics. Fungal Genet. Biol. 82:22-31.

Kelly, A. C., Proctor, R. H., Belzile, F., Chulze, S. N., Clear, R. M., Cowger, C., Elmer, W., Lee, T., Obanor, F., Waalwijk, C., and Ward, T. J. 2016. The geographic distribution and complex evolutionary history of the NX-2 trichothecene chemotype from Fusarium graminearum. Fungal Genet. Biol. 95:39-48.

Kelly, A. C., and Ward, T. J. 2018. Population genomics of Fusarium graminearum reveals signatures of divergent evolution within a major cereal pathogen. PLoS One 13:e0194616.

Kuhnem, P. R., Spolti, P., Del Ponte, E. M., Cummings, J. A., and Bergstrom, G. C. 2015. Trichothecene genotype composition of Fusarium graminearum not differentiated among isolates from maize stubble, maize ears, wheat spikes, and the atmosphere in New York. Phytopathology 105: 695-699.
Kuhnem, P. R., Ward, T. J., Silva, C. N., Spolti, P., Ciliato, M. L., Tessmann, D. J., and Del Ponte, E. M. 2016. Composition and toxigenic potential of the Fusarium graminearum species complex from maize ears, stalks and stubble in Brazil. Plant Pathol. 65:1185-1191.

Lenth, R. 2019. Estimated Marginal Means, aka Least-Squares Means. R Package version 1.3.4. https://cran.r-project.org/web/packages/emmeans/index.html

Leplat, J., Friberg, H., Abid, M., and Steinberg, C. 2013. Survival of Fusarium graminearum, the causal agent of Fusarium head blight. A review. Agron. Sustain. Dev. 33:97-111.

Leslie, J. F., and Summerell, B. A., eds. 2006. The Fusarium Laboratory Manual. Blackwell Publishing, Hoboken, NJ, U.S.A.

Liang, J., Lofgren, L., Ma, Z., Ward, T. J., and Kistler, H. C. 2015. Population subdivision of Fusarium graminearum from barley and wheat in the upper Midwestern United States at the turn of the century. Phytopathology 105:1466-1474.

Liang, J. M., Xayamongkhon, H., Broz, K., Dong, Y., McCormick, S. P., Abramova, S., Ward, T. J., Ma, Z., and Kistler, H. C. 2014. Temporal dynamics and population genetic structure of Fusarium graminearum in the upper Midwestern United States. Fungal Genet. Biol. 73:83-92.

Lofgren, L. A., Leblanc, N. R., Certano, A. K., Nachtigall, J., Labine, K. M., Broz, K., Dong, Y., Bethan, B., Kafer, C. W., and Kistler, H. C. 2017. Fusarium graminearum: Pathogen or endophyte of North American grasses? New Phytol. 217:1203-1212.

Lofgren, L. A., Riddle, J., Dong, Y., Kuhnem, P. R., Cummings, J. A., Del Ponte, E. M., Bergstrom, G. C., and Kistler, H. C. 2018. A high proportion of NX-2 genotype strains are found among Fusarium graminearum isolates from northeastern New York State. Eur. J. Plant Pathol. 150:791-796.

Malihipour, A., Gilbert, J., Piercey-Normore, M., and Cloutier, S. 2012. Molecular phylogenetic analysis, trichothecene chemotype patterns, and variation in aggressiveness of Fusarium isolates causing head blight in wheat. Plant Dis. 96:1016-1025.

McMullen, M., Bergstrom, G., De Wolf, E., Dill-Macky, R., Hershman, D., Shaner, G., and Van Sanford, D. 2012. A unified effort to fight and enemy of wheat and barley: Fusarium head blight. Plant Dis. 96:1712-1728.

Meirmans, P. G. 2006. Using the AMOVA framework to estimate a standardized genetic differentiation measure. Evolution 60:2399-2402.

Meirmans, P. G., and Hedrick, P. W. 2011. Assessing population structure: $F_{S T}$ and related measures. Mol. Ecol. Resour. 11:5-18.

Miedaner, T., Cumagun, C. J. R., and Chakraborty, S. 2008. Population genetics of three important head blight pathogens: Fusarium graminearum, $F$. pseudograminearum and F. culmorum. J. Phytopathol. 156:129-139.

Naef, A., and Défago, G. 2006. Population structure of plant-pathogenic Fusarium species in overwintered stalk residues from Bt-transformed and non-transformed maize crops. Eur. J. Plant Pathol. 116:129-143.

Nei, M. 1978. Estimation of average heterozygosity and genetic distance from a small number of individuals. Genetics 89:583-590.

O’Donnell, K., Kistler, H. C., Tacke, B. K., and Casper, H. H. 2000. Gene genealogies reveal global phylogeographic structure and reproductive isolation among lineages of Fusarium graminearum, the fungus causing wheat scab. Proc. Natl. Acad. Sci. U.S.A. 97:7905-7910.

O’Donnell, K., Ward, T. J., Geiser, D. M., Kistler, H. C., and Aoki, T. 2004. Genealogical concordance between the mating type locus and seven other nuclear genes supports formal recognition of nine phylogenetically distinct species within the Fusarium graminearum clade. Fungal Genet. Biol. 41: $600-623$

Oksanen, J., Blanchet, F. G., Friendly, M., Kindt, R., Legendre, P., McGlinn, D., Minchin, P. R., O’Hara, R. B., Simpson, G. L., Solymos, P., Henry, M., Stevens, H., Szoecs, E., and Wagner, H. 2018. vegan: Community Ecology Package. R Package version 2.5. https://cran.r-project.org/web/packages/ vegan/index.html

Pasquali, M., Beyer, M., Logrieco, A., Audenaert, K., Balmas, V., Basler, R., Boutigny, A. L., Chrpova, J., Czembor, E., Gagkaeva, T., Gonzalez-Jaen, M. T., Hofgaard, I. S., Koycu, N. D., Hoffman, L., Levic, J., Marin, P., Miedaner, T., Migheli, Q., Moretti, A., Muller, M. E. H., Munaut, F., Parikka, P., Pallez-Barthel, M., Piec, J., Scauflaire, J., Scherm, B., Stankovic, S., Thrane, U., Uhlig, S., Vanheule, A., Yli-Mattila, T., and Vogelgsang, S. 2016. A European database of Fusarium graminearum and F. culmorum trichothecene genotypes. Front. Microbiol. 7:406.

Peakall, R., and Smouse, P. E. 2006. GenALEx 6: Genetic analysis in Excel. Population genetic software for teaching and research. Mol. Ecol. Notes 6: 288-295.

Peakall, R., and Smouse, P. E. 2012. GenALEx 6.5: Genetic analysis in Excel. Population genetic software for teaching and research-An update. Bioinformatics 28:2537-2539.

Pielou, E. C. 1975. Ecological Diversity. Wiley, New York, NY, U.S.A.

Prim, R. C. 1957. Shortest connection networks and some generalizations. Bell Syst. Tech. J. 36:1389-1401.

Prussin, A. J., II, Li, Q., Malla, R., Ross, S. D., and Schmale, D. G., III. 2014. Monitoring the long-distance transport of Fusarium graminearum from field-scale sources of inoculum. Plant Dis. 98:504-511. 
RStudio Development Team. 2016. RStudio, version 1.1.453. https:// www.npackd.org/p/rstudio/1.1.453

Sampietro, D. A., Díaz, C. G., Gonzalez, V., Vattuone, M. A., Ploper, L. D., Catalan, C. A. N., and Ward, T. J. 2011. Species diversity and toxigenic potential of Fusarium graminearum complex isolates from maize fields in northwest Argentina. Int. J. Food Microbiol. 145:359-364.

Schmale, D. G., Leslie, J. F., Zeller, K., Saleh, A., Shields, E. J., and Bergstrom, G. C. 2006. Genetic structure of atmospheric populations of Gibberella zeae. Phytopathology 96:1021-1026.

Schmale, D. G., Wood-Jones, A. K., Cowger, C., Bergstrom, G. C., and Arellano, C. 2011. Trichothecene genotypes of Gibberella zeae from winter wheat fields in the eastern USA. Plant Pathol. 60:909-917.

Scoz, L. B., Astolfi, P., Reartes, D. S., Moraes, M. G., and Del Ponte, E. M. 2009. Trichothecene mycotoxin genotypes of Fusarium graminearum sensu stricto and Fusarium meridionale in wheat from southern Brazil. Plant Pathol. 58:344-351.

Shannon, C. E. 1948. A mathematical theory of communication. Bell Syst. Tech. J. 27:379-423.

Simpson, E. H. 1949. Measurement of diversity. Nature 163:688.

Sneideris, D., Ivanauskas, A., Suproniene, S., Kadziene, G., and Sakalauskas, S. 2018. Genetic diversity of Fusarium graminearum isolated from weeds. Eur. J. Plant Pathol. 153:639-643.

Starkey, D. E., Ward, T. J., Aoki, T., Gale, L. R., Kistler, H. C., Geiser, D. M., Suga, H., Tóth, B., Varga, J., and O'Donnell, K. 2007. Global molecular surveillance reveals novel Fusarium head blight species and trichothecene toxin diversity. Fungal Genet. Biol. 44:1191-1204.

Stoddart, J. A., and Taylor, J. F. 1988. Genotypic diversity: Estimation and prediction in samples. Genetics 118:705-711.

Suga, H., Gale, L. R., and Kistler, H. C. 2004. Development of VNTR markers for two Fusarium graminearum clade species. Mol. Ecol. Notes 4: 468-470.

Talas, F., and McDonald, B. A. 2015. Genome-wide analysis of Fusarium graminearum field populations reveals hotspots of recombination. BMC Genomics 16: Article 996.

Turkington, T. K., Clear, R. M., Demeke, T., Lange, R., Xi, K., and Kumar, K. 2011. Isolation of Fusarium graminearum from cereal, grass and corn residues from Alberta, 2001-2003. Can. J. Plant Pathol. 33:179186.

USDA National Agricultural Statistics Service. 2019. Cropland Data Layer. https://nassgeodata.gmu.edu/CropScape/

van der Lee, T., Zhang, H., van Diepeningen, A., and Waalwijk, C. 2015. Biogeography of Fusarium graminearum species complex and chemotypes: A review. Food Addit. Contam. 32:453-460.

Varga, E., Wiesenberger, G., Hametner, C., Ward, T. J., Dong, Y., Schöfbeck, D., McCormick, S., Broz, K., Stückler, R., Schuhmacher, R., Krska, R., Kistler, H. C., Berthiller, F., and Adam, G. 2015. New tricks of an old enemy: Isolates of Fusarium graminearum produce a type A trichothecene mycotoxin. Environ. Microbiol. 17:2588-2600.

Venables, W. N., and Ripley, B. D. 2002. Modern Applied Statistics with S, Fourth ed. Springer, New York, NY, U.S.A.

Vogelgsang, S., Widmer, F., Jenny, E., and Enkerli, J. 2009. Characterisation of novel Fusarium graminearum microsatellite markers in different Fusarium species from various countries. Eur. J. Plant Pathol. 123:477-482.

Wang, J. H., Ndoye, M., Zhang, J. B., Li, H. P., and Liao, Y. C. 2011. Population structure and genetic diversity of the Fusarium graminearum species complex. Toxins (Basel) 3:1020-1037.

Ward, T. J., Clear, R. M., Rooney, A. P., O’Donnell, K., Gaba, D., Patrick, S., Starkey, D. E., Gilbert, J., Geiser, D. D., and Nowicki, T. W. 2008. An adaptive evolutionary shift in Fusarium head blight pathogen populations is driving the rapid spread of more toxigenic Fusarium graminearum in North America. Fungal Genet. Biol. 45:473-484.

Winter, D. J. 2012. MMOD: An R library for the calculation of population differentiation statistics. Mol. Ecol. Resour. 12:1158-1160.

Yang, M., Zhang, H., Kong, X., Van Der Lee, T., Waalwijk, C., van Diepeningen, A., Xu, J., Xu, J., Chen, W., and Feng, J. 2018. Host and cropping system shape the Fusarium population: 3ADON-producers are ubiquitous in wheat whereas NIV-producers are more prevalent in rice. Toxins (Basel) 10:115.

Zhang, H., van der Lee, T., Waalwijk, C., Chen, W., Xu, J., Xu, J., Zhang, Y., and Feng, F. 2012. Population analysis of the Fusarium graminearum species complex from wheat in China show a shift to more aggressive isolates. PLoS One 7:e31722. 